NICOLE CRISTI ROJAS

ESCUELA DE DISEÑO

FACULTAD DE ARQUITECTURA, DISEÑO,

ESTUDIOS URBANOS Y TERRITORIALES

PONTIFICIA UNIVERSIDAD CATÓLICA

SANTIAGO, CHILE

NACRISTI@UC.CL

JAVIERA MANZI

NÚCLEO DE GRÁFICA Y

MOVILIZACIÓN ESTUDIANTIL

UNIVERSIDAD DE CHILE

SANTIAGO, CHILE

JAVIERA.MANZI@GMAIL.COM
La presente investigación contó en el apoyo de financiamiento del Consejo Nacional de la Cultura y las Artes, fondart nacional, Investigación 2013, modalidad única.

Fecha de recepción: 01/07/2017

Fecha de aceptación: 06/11/2017

Cómo citar: Cristi, N. y Manzi, J. (2017).

Construcción de una trinchera gráfica: la

experiencia de la Agrupación de Plásticos Jóvenes

(APJ) y el Tallersol durante la dictadura en Chile.

RChD: creación y pensamiento, 2(3), 1-14.

DOI: $10.5354 / 0719-837 \times .2017 .47690$

Revista Chilena de Diseño

RChD: creación y pensamiento

Universidad de Chile

2017, 2(3)

http://rchd.uchile.cl

\section{Construcción de una trinchera gráfica: la experiencia de la Agrupación de Plásticos Jóvenes (APJ) y el Tallersol durante la dictadura en Chile}

\author{
Building a graphic trench: the experience of the Agrupación de \\ Plásticos Jóvenes (APJ) and Tallersol during Chile's dictatorship
}

Resumen. El papel político que tuvo el cartelismo en Chile como un medio de promoción y agitación sufrió una profunda redefinición desde el período de la Unidad Popular, en que se despliega una utopía gráfica que luego tras el golpe militar es asumida como práctica de resistencia. El presente artículo busca ahondar en la pregunta por la relación entre gráfica y política durante la década de los setenta y ochenta a partir de la experiencia de dos colectivos: la Agrupación de Plásticos Jóvenes (APJ) y el Centro Cultural Tallersol, ambos ubicados en Santiago de Chile. La forma en que politizan la práctica gráfica da lugar a una ampliación de lo político en tanto contenido o consigna, para dar lugar a la politización de sus procedimientos y a sus modos de hacer con otros. De este modo, se traslada la concepción de la pieza gráfica entendida como instrumento de propaganda, a la concepción de esta como resultado de un entramado de complicidad y experimentación mancomunada, una experiencia de producción que permite la construcción y expansión de una trinchera gráfica.

Palabras clave: dictadura militar en Chile, gráfica, práctica política, resistencia, vínculo social gráfico.

\begin{abstract}
The political role that posters had in Chile as a medium of promotion and agitation underwent a deep redefinition since the period of the Popular Unity, during which a graphic utopia emerges, that after the military coup is assumed as a practice of resistance. This article seeks to delve into que question of the relationship between graphic activity and politics during the 1970 s and 1980 s through the experience of two collectives: the Agrupación de Plásticos Jóvenes (APJ, "Young Plastic Artists Association") and Tallersol, both based in Santiago, Chile. The mode in which they politicize the graphic practice gives way to a broadening of the political, in term of its content or slogans, opening in turn a space for the politicization of its procedures and ways of creating with others. Thus, the notion of the graphic piece understood as an instrument of propaganda is displaced toward the concept of it as a result of an interweaving of complicity and joint experimentation, an experience of production that enables the construction and expansion of a graphic trench.
\end{abstract}

Keywords: graphic activity, graphic social bond, military dictatorship in Chile, political practice, resistance. 
1. Durante los años sesenta y con mayor

desarrollo entre 1970 y 1973, el diseño tuvo una participación activa en los procesos de transformación en curso. Como parte de este importante involucramiento se encuentra el trabajo de Gui Bonsiepe y el Grupo de Diseño Industrial; el proyecto de Moda Autóctona en el ámbito textil y de vestuario, donde destacan figuras como Enrique Concha, Nelly Alarcón y María Inés Solimano. En el área gráfica es posible identificar una vertiente racionalista, liderada por Pepa Foncea y por otro lado, el trabajo gráfico de Vicente y Antonio Larrea, Luis Albornoz, Waldo González y Mario Quiroz, entre otras iniciativas que concibieron el diseño como un agente de transformación social y un factor relevante que debía hacerse parte de la llamada vía chilena al socialismo.

\section{Introducción}

El golpe de Estado de 1973 marca un punto de inflexión en la historia de Chile, una escisión que interrumpe el curso de transformaciones políticas, sociales y culturales de las que tanto el diseño ${ }^{1}$ como las artes visuales venían formando parte, entre otras cosas a partir del desarrollo de la comunicación gráfica vinculada a estos procesos. Ya en dictadura, y como toda forma de producción situada, la gráfica en tanto medio de comunicación y propagación crítica, cambia de autores, formatos, técnicas y espacios de circulación; cambia fundamentalmente su forma de vincularse y producir políticamente. En este contexto, los modos de la relación entre gráfica y política aparece transformada en experiencias tal como la de la Agrupación de Plásticos Jóvenes (1979-1987) y el Centro Cultural Tallersol (1977).

A lo largo de sus trayectorias, ambos colectivos realizaron cientos de afiches para organizaciones populares, partidos de izquierda, coordinadoras culturales, grupos musicales, sindicatos, organismos de derechos humanos, grupos estudiantiles, entre otros, asumiendo esta tarea de producción como parte de la construcción de una trinchera gráfica (Pérez, 2014) en resistencia. Un espacio de lucha y organización del quehacer gráfico que se mantuvo autónomo de partidos e instituciones, pero a la vez profundamente integrado en la red de organizaciones y movimientos sociales contrarios al régimen. Lejos del tiraje masivo, el financiamiento estatal y la alta difusión del cartel de la Unidad Popular, la comunicación gráfica de estas trincheras subsistió al ocultamiento del trazo (Castillo, 2009 p. 42) inicial que trajo la dictadura a partir del esfuerzo de colectivos que debieron manipular tecnologías, concebir nuevos procedimientos, adaptar formatos y renovar lenguajes. En esta línea, el presente artículo se adentra en este capítulo de la historia del afiche político en Chile centrándose no en un análisis del resultado gráfico en sí mismo, sino más bien en la gráfica como una práctica de resistencia, un ejercicio colectivo de la gráfica que politiza los procedimientos técnicos así como los vínculos sociales que hacen posible la producción de cada afiche. Lejos de una compilación de piezas aisladas, se busca concebir el desarrollo gráfico de este período como una entramado creativo, cómplice y de recursos mínimos. Para ello se propone: 1) presentar como antecedente la relación entre gráfica y política durante la Unidad Popular en Chile, 2) describir los cambios en el contexto político y social de producción que afectaron a la gráfica tras el golpe de Estado en Chile, 3) exponer las formas de politización de las prácticas gráficas en Chile y América Latina durante los años ochenta, 4) describir los elementos comunes que comparten la experiencia de la APJ y el Tallersol, 5) analizar las formas que toma la relación entre gráfica y política como prácticas de resistencia a la dictadura cívico-militar. Lo que aquí se presenta, se corresponde con la investigación realizada por ambas autoras y publicada en el libro Resistencia Gráfica. Dictadura en Chile. APJ-Tallersol (Cristi \& Manzi, 2016). En esta se llevó a cabo un proceso de producción de información que contempló la realización y análisis de diez entrevistas en profundidad individuales, una entrevista grupal, tres encuentros de análisis colectivo junto a gráficos y especialistas, revisión de bibliografía y textos históricos, investigación de archivos y finalmente el análisis visual de más de 300 piezas gráficas.

\section{Cambios en la práctica gráfica: Desde la utopía a la resistencia gráfica}

El auge del cartelismo durante el gobierno de la Unidad Popular (19701973) fue uno de los principales medios que tuvo tanto el Estado como los 


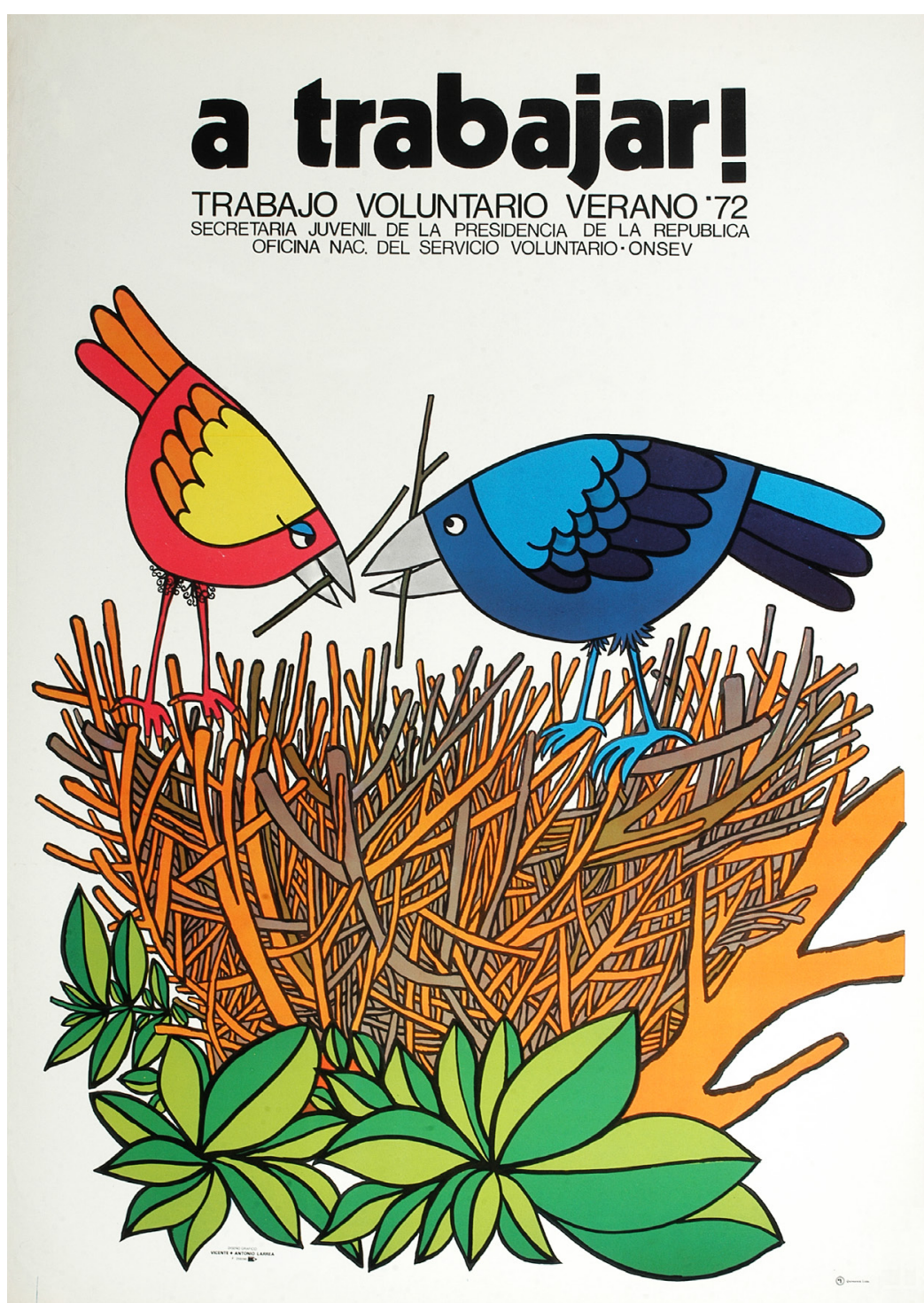

partidos políticos para la difusión de sus programas, la propagación de ideas y candidaturas, e incluso para una pedagogía social respecto a las reformas y el proyecto socialista en curso en el espacio público (Vico y Osses, 2009). Durante este período, el estado financió el diseño y reproducción de piezas gráficas que empapelaron la ciudad, que iban desde el medio mercurio $(55 \times 77 \mathrm{~cm})$ al tamaño mercurio $(110 \times 77 \mathrm{~cm})$, y que contaron una amplia variedad de colores y tintas que permitieron un acercamiento a una estética psicodélica que influenció fuertemente el período (Vico y Osses, 2009). A su vez, la masiva reproductibilidad de la serigrafía y el offset, las dos principales tecnologías utilizadas en el período, conllevó la posibilidad de acercar el arte a las masas, como diría el nombre de la exposición serigráfica que se desarrolló simultáneamente en 80 diferentes localidades a los largo de todo Chile en 1970, por medio de la reproductibilidad, "El pueblo tiene arte con Allende". La "utopía gráfica" (Cristi y Manzi, 2016) constituye aquella síntesis propia del período de la Unidad Popular, donde el lenguaje gráfico formó parte de la
Figura 1. Afiche desarrollado en el gobierno de la Unidad Popular. "A Trabajar", 1972, Vicente Larrea, Antonio Larrea, Luis Albornoz. Offset. Fuente: Archivo FADEU, UC. Fondo Larrea - Albornoz. 
expansión y expresión de los proyectos emancipatorios en despliegue. Tanto en el campo del diseño como en el de las artes, su desarrollo técnico y visual encarnó los procesos de modernización y transformación social en curso. Tras la arremetida militar afiches, panfletos y pasquines políticos y de organizaciones sociales salieron rápidamente de circulación abierta y pasaron a ser un flanco de la censura oficial. El despliegue de la gráfica política se retiró de las principales avenidas y oficinas de diseño, para llegar a subsistir como una práctica de producción subterránea, en muchos casos clandestina, vinculada a autodidactas, artistas, trabajadores de la cultura y estudiantes que siguieron diseñando, imprimiendo y distribuyendo afiches durante los 17 años de dictadura cívico-militar. Frente a la imposición de un estado de sitio y a la clausura general del espacio público, uno de los primeros signos en aparecer entre los muros de la ciudad, es la marca anónima de una $\mathrm{R}$ rodeada por un círculo que se repite en los muros de la ciudad. Este gesto contestatario, que tiene una primera aparición tímida, pequeña y por lo general aislada, pronto comenzará a proliferar y repetirse por el espacio público como la primera marca de una presencia obstinada y clandestina. En un capítulo de su inconclusa tesis La creación artística como lenguaje de resistencia a la dictadura militar, Alberto Pérez, otrora artista del grupo Signo, observa que al rayado de la R le seguirá una vía caligráfica, popular, primaria (Pérez, 1986) y de mínimos recursos, con la que las organizaciones sociales comenzaron a elaborar los primeros afiches y volantes. Para el autor, estas fueron las primeras expresiones gráficas con que se agita y difunde mediante soportes elaborados entre la improvisación y la urgencia. Se trata de un trabajo de "equipos muy pequeños, talleres caseros, impresores y gráficos que realizan tareas menudas, sellos, carteles en blanco y negro diseñados para ser pegados en postes, muros de fábricas e industrias, o que se incorporan a las publicaciones clandestinas mimeografiadas" (Pérez, 1986). Para Pérez, la gráfica, como respuesta impaciente, será -junto con la música- uno de los medios de expresión pioneros para dar cauce al desacato y el reconocimiento de signos comunes dentro de la resistencia. A las primeras expresiones más impacientes, le siguen la conformación de colectivos y espacios cada vez más especializados en la tarea de producir afiches, panfletos y material impreso que circularía en vías alternativas, es precisamente en este contexto que emergen grupos como la APJ y el Centro Cultural Tallersol (Cristi y Manzi, 2016).

El Centro cultural Tallersol (1977), además de ser el primer centro cultural autónomo fundado en dictadura, fue un espacio de producción gráfica que se mantuvo y se mantiene activo hasta el día de hoy de la mano de su director Antonio Kadima. En un primer momento, el diseño de afiches, dípticos y volantes que ahí se desarrolló estuvo a cargo del Taller Nueva Gráfica conformado por Kadima, junto al ilustrador Eduardo Gallegos y el diseñador Felipe Martínez, quienes trabajaron colectivamente entre 1980 y 1982. Luego de este período, Martínez y Gallegos siguieron trabajando juntos en un rubro más comercial de diseño y Kadima se hizo cargo del taller de gráfica del Tallersol bajo el nombre de Taller de gráfica. Desde entonces y a pesar de trabajar de manera más individual en el diseño, mantuvo una permanente vinculación con otros artistas gráficos y serigrafistas que habitaron o se desempeñaron en este espacio. Tal es el caso de Danilo Bahamondes (más conocido entonces como El Gitano) quien junto a los serigrafistas Juan Carlos Gallardo y Antonio Rojas, imprimió en el Tallersol bajo la firma de Arauco y trabajó en las primeras intervenciones de la Brigada Chacón. Durante la dé- 
cada de los ochenta, el centro cultural cambió su domicilio en tres ocasiones, pero en cada lugar abrió sus puertas a decenas de artistas, organizaciones de derechos humanos, grupos de propaganda, sindicatos, músicos y poetas nacionales, esto es, un amplio espectro de organizaciones de oposición lo adoptaron como su espacio de actividad y reunión. ${ }^{2}$

La Agrupación de Plásticos Jóvenes (APJ) fue fundada en 1979 por estudiantes y egresados de artes de la Universidad de Chile y se mantuvo activa hasta 1987, año en que realizan su última acción pública. Desde la convocatoria a los Plásticos Jóvenes que realizan Havilio Pérez y Hugo Sepúlveda, esta es concebida como una orgánica abierta para reunir a jóvenes artistas y trabajadores de la cultura con el fin de generar un referente propio en oposición a la dictadura. A lo largo de su existencia, la AP se abocó al desarrollo de cuatro líneas de acción colectiva: la realización de murales en poblaciones y sedes sociales, escenografía de actos culturales, acciones de arte en el espacio público y la producción de afiches e intervenciones gráficas. Con un repertorio amplio y diverso, la gráfica de la APJ se caracterizó tanto por la experimentación constante de lenguajes y técnicas, como por el compromiso con organizaciones de pobladores, sindicatos, grupos estudiantiles, organizaciones de derechos humanos y espacios culturales. De su organización asamblearia llegaron a participar más de 500 personas, entre ellas Alberto Díaz Parra, Víctor Hugo Codoceo, Patricio Rueda, Leonardo Infante, Sonia de los Reyes, Janet Toro, Cucho Márquez, Mario Rosseti, Iván Godoy, Ana María Cisternas, Evelyn Fuchs y Claudia Winther.

\section{Golpes a la gráfica en dictadura}

Desde el mismo 11 de septiembre, la Junta Militar de Gobierno presidida por Augusto Pinochet canceló la Constitución de 1925, vigente hasta ese momento, y comienza a hacer efectivos los dispositivos represivos y el aparato legal por medio de bandos y decretos leyes, en reemplazo de las leyes de la república al amparo del estado de sitio. Uno de los primeros bandos en publicarse, a tan solo cinco días del golpe, se refiere al veto sobre la propaganda impresa: "Toda persona que sea sorprendida durante el Estado de Sitio imprimiendo o difundiendo por cualquier medio propaganda subversiva y atentatoria contra el Gobierno Supremo sufrirá las penas contempladas por el código de Justicia Militar para tiempo de guerra" (El Mercurio, 1973). Esta temprana proscripción es quizás una de las más claras expresiones de la importancia que tuvo para la dictadura extinguir la producción y difusión de material impreso como práctica disuasiva. En una línea similar, en relación al panfleto, el Decreto Ley 1009 de 1975, declara que “...se presumirá autor de propaganda de doctrinas o de propagar o divulgar noticias o informaciones que las leyes describan como delito al que sea sorprendido portando volantes, panfletos o folletos para su difusión" (Valdebenito, 2010). La impresión y distribución de material impreso, de toda forma de gráfica política no oficialista, pasó a ser un acto de desacato perseguido por el régimen.

La brillante cuatricromía y los grandes formatos de los afiches que se venían realizando durante la UP, fue abruptamente interrumpida. Los muros de calles y avenidas que solían estar empapelados con carteles y murales de brigadas como la Ramona Parra y la Elmo Catalán fueron desprendidos y cubiertos de blanco como parte de la llamada Operación Limpieza (Errázuriz y Leiva, 2012) que llevó a cabo el régimen con la ayuda de redadas civiles que se encargaron de tapar toda propaganda y signo que remitiera al pasado

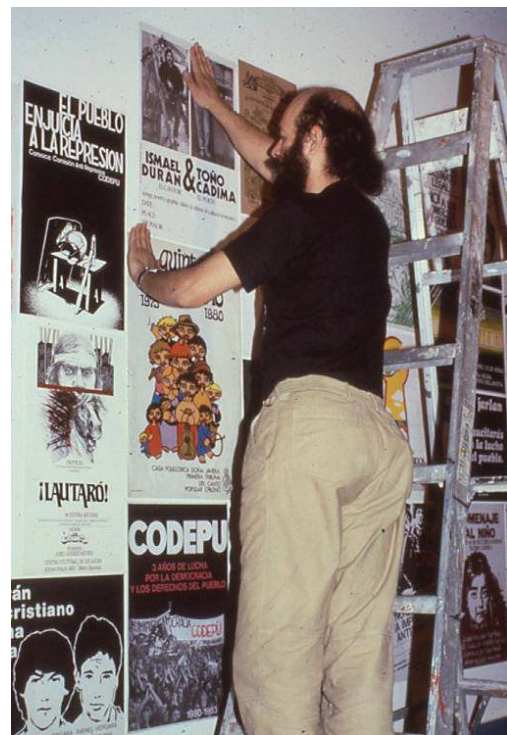

Figura 2. Fotografía de exposición de afiches del Tallersol en Berkeley California, EUA, 1986. En la fotografía Antonio Kadima. Fuente: Archivo Memoria de la Resistencia, Tallersol.

2. Este espacio sigue abierto y activo gracias a la persistencia de su fundador quien hasta el día 5 abre sus puertas en el la casa en que hoy se emplaza el Tallersol en pleno barrio Yungay, pleno centro de Santiago, a creadores, organizaciones sociales y grupos de contracultura. 
socialista. De este modo, la violencia desnuda de la investida militar que persiguió, torturó, ejecutó e hizo desaparecer a miles de personas, tuvo como correlato la violencia simbólica de un régimen que extirpará todo signo y rastro visible de la izquierda en el espacio público. Los primeros dos años representaron a nivel cultural "la desinfección del pasado marxista y, por otra, la promoción de una noción militarizada de la estética cotidiana, que se refleja en rasgos tales como la depuración, el orden y la restauración fervorosa de los símbolos patrios" (Errázuriz y Leiva, 2012, p. 15). La ciudad de Santiago, como tantas otras localidades a largo de Chile, se acercó catastróficamente a la imagen que anticipó Ana Cortés cuando, en pleno desarrollo del afichismo en Chile, planteó que "una ciudad sin gritos pegados en los muros sería hoy en día casi una ciudad silenciosa" (1937).

\section{Gráfica y política en América Latina durante los años ochenta}

En el contexto de las dictaduras y las crisis de Estado que azotaron la región durante la década de los setenta y ochenta, la producción gráfica y más ampliamente las prácticas artísticas del período redefinen el marco de la relación entre arte y política abriendo paso a la emergencia de prácticas creativas en procesos de movilización y ocupación del espacio público. Esto ha sido estudiado por Ana Longoni junto a la Red de Conceptualismos del Sur a partir de la concepción de activismos artísticos, la que agrupa "bajo esta definición producciones y acciones, muchas veces colectivas, que abrevan en recursos artísticos con la voluntad de tomar posición e incidir de alguna forma en el territorio de lo político" (Longoni, 2009, p. 18). Más que tratarse de un movimiento o estilo, el activismo artístico que emerge en América Latina en contextos de dictadura o crisis de Estado, refiere a aquellos "modos de producción de formas estéticas y de relacionalidad que anteponen la acción social a la tradicional exigencia de autonomía del arte" (Expósito, Vidal y Vindel 2012, p. 279). En efecto, a diferencia de grupos de agitación y propaganda, el "activismo artístico, en definitiva, suele tematizar 'la política'. Pero lo verdaderamente relevante es cómo contribuye a 'producir' política: cómo constituye lo político en acto" (Expósito, Vidal y Vindel, op. cit., p. 282). En el caso de la producción gráfica en los años ochenta, es posible rescatar experiencias donde la política de las consignas e imágenes reproducidas, tuvo como correlato prácticas colectivas que promovieron la socialización de las técnicas y el uso de recursos mínimos. En Argentina, Perú y Chile, la serigrafía tomó un nuevo impulso donde no bastaba ya la idea utópica de la democratización asociada a su capacidad de reproducción, sino que "adquiere un nuevo sentido político en la búsqueda de un arte participativo como un nuevo género cuyo concepto es usar las calles como soporte de arte [...] y a los movimientos sociales como su soporte social” (López, 2012, p. 319). En este contexto, el lenguaje gráfico incorporó elementos irónicos y lúdicos, los que se conjugan con una fuerte confrontación política con los regímenes dominantes. Tal es el caso de grupos como GAS-TAR (Grupo de Artistas Socialistas - Taller de Arte Revolucionario), luego llamado C.A.Pa.Ta. co (Colectivo de Arte Participativo Tarifa Común) conformado por artistas provenientes de la vanguardia experimental peruana y argentina, quienes colaboran en movilizaciones convocadas por movimientos de derechos humanos y sindicatos obreros con acciones gráficas callejeras. En otra latitud, el Taller NN (1988-1991) conformado en Perú por un grupo de arquitectos autodidactas que abrieron talleres de discusión y producción gráfica cola- 
borativa, inmersos en la escena del underground limeño, generaron escenografías para teatro y recitales punk, obras para ciclos de cine, impresión de poemarios artesanales, así como múltiples piezas de agitación política radical. Desde esta perspectiva, es posible adentrarse a concebir estas acciones como parte de un activismo gráfico donde el lugar de la política se expande hacia los modos de hacer, de visibilizar y de desbordar los límites autorales y técnicos de la creación impresa.

Desde la perspectiva de un activismo gráfico, la demanda que anuncian los afiches por justicia, libertad y democracia toma forma no solo a nivel de consigna, sino más ampliamente como parte de los modos de hacer y organizarse, de manipular medios técnicos y producir desde recursos mínimos.

Desde esta perspectiva, la politización de la práctica gráfica implica tanto el involucramiento en procesos de lucha con otras organizaciones y espacios, como la micropolítica de un quehacer que subvierte la atomización y el quiebre del tejido social. De este modo cada momento de la producción de un afiche forma parte del despliegue de una política gráfica cuyo centro no es ya el afiche final, sino la manipulación de los medios y la conformación de una trama cómplice de vínculos sociales gráficos (Cristi y Manzi, 2016). En El autor como productor, Walter Benjamin discute la tendencia a valorar la cualidad política e incluso revolucionaria a partir del mensaje o contenido de las obras, sin prestar atención a sus condiciones materiales, es decir, a los modos en que ha sido producida. Desde esta perspectiva, la potencia transformadora de una obra toma forma en el modo en que se enfrenta con las restricciones del medio social y el aparato técnico en que está inserto. "Antes de la pregunta: ¿cuál es la actitud de una obra frente a las relaciones de producción de la época?, quisiera preguntar: ¿cuál es su posición dentro de ellas?" (Benjamin, 2005). La toma de una posición de resistencia, no es tanto la tendencia que pueda declararse, la consigna con que se encabeza el afiche, sino la posibilidad de hacer de la producción, de la manipulación de los medios y la superación de sus restricciones, una instancia política tan significativa como el fin último de este proceso.

\section{La conformación de una trinchera gráfica}

A pesar de la diferencias en su trayectoria y conformación, la Agrupación de Plásticos Jóvenes y el Centro Cultural Tallersol en tanto agentes de una gráfica activista y autónoma, conformaron un medio gráfico compartido, una verdadera trinchera gráfica, desde la que llegaron a politizar y comprometer su práctica como colectivos gráficos. La figura de la trinchera que evoca las zanjas en medio del campo de batalla nos permite concebir la idea de un espacio de acción que es al mismo tiempo un lugar de encuentro y confrontación, de profundización de lo común (la excavación de la trinchera) y de respuesta contra el régimen imperante. La política de la trinchera no se corresponde solo con la dirección a la que apuntan los dardos, sino con la construcción de un medio común desde donde tomar y ganar posición. Entre los rasgos centrales de esta política gráfica se encuentra el compromiso con que respondieron a la contingencia del movimiento social, la colectivización de la autoría así como su autonomía frente a partidos e instituciones, el trabajo en redes de colaboración y complicidad tanto con quienes les solicitaban los afiches como con los trabajadores y operarios de imprentas, y el ímpetu de manipulación y experimentación a partir de recursos técnicos y materiales limitados. 


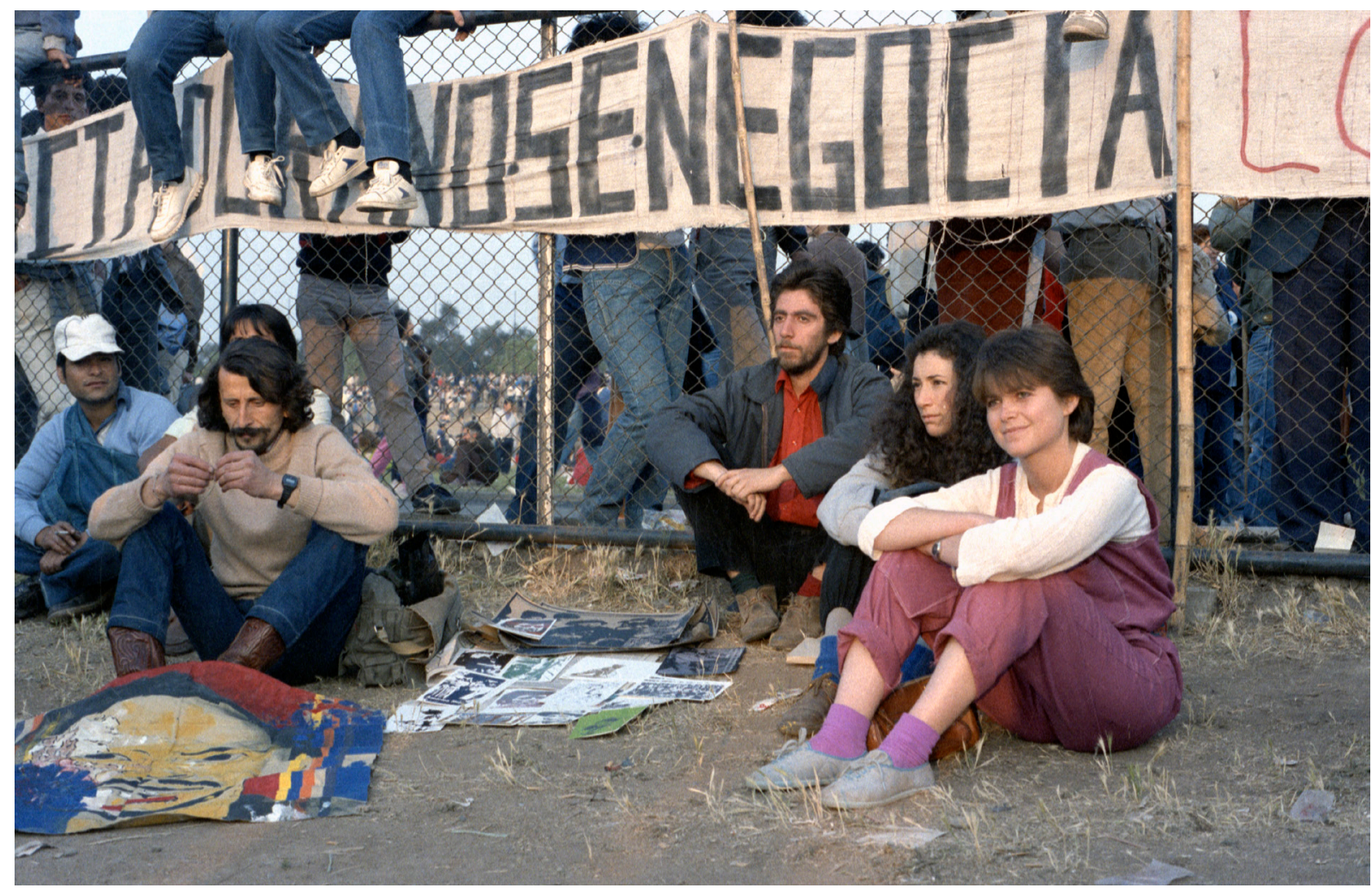

Figura 3. Fotografía de APJ en Parque O'Higgins, 1985. Fuente: Archivo personal de Cucho Márquez.
Un primer elemento de la política gráfica de ambos grupos es su compromiso profundo con la contingencia de su tiempo o de manera más precisa, con la permanente falta de tiempo. En palabras de los gráficos, frente a todo encargo que llegara "lo primero que preguntábamos era para cuándo" (Kadima, 2013), toda la organización del trabajo dependía de la posibilidad de responder rápidamente al pulso de la contingencia. Una carrera contra el tiempo que resultaba inevitable cuando lo que estaba en juego era terminar el afiche que sería ocupado en la marcha del día siguiente o la difusión del pliego con las reivindicaciones de la huelga que ya había comenzado. Lo que primó fue la capacidad de improvisar frente a la permanente falta de tiempo, y de anticipar creativamente los innumerables contratiempos. Fue a partir de esa creatividad práctica la que contra todo pronóstico hizo que fuera posible conseguir la foto de militantes detenidos, las tintas para las serigrafías; o lograr que la imprenta recibiera sus diseños durante la noche previa a la manifestación. Un ímpetu de respuesta que también los llevó a innovar en formatos y medios gráficos, dando al diseño de piezas que, a través de la serialización de imágenes y la omisión de texto dentro del diseño, permitía la renovación constante de consignas, maximizando su funcionalidad y minimizando los costos de producción. Estos afiches abiertos como les llamaron en la APJ, pretendían en palabras de Alberto Díaz, responder al hecho de que "la contingencia era tan rápida que día a día las consignas iban cambiando, entonces cuando le preguntábamos a la gente sobre qué poner, optamos por eso, dejar los afiches abiertos para que los llenaran con la mano de ellos" (Díaz, 2013). Mediante esta operación, el afiche no funciona como soporte de un enunciado fijo y previamente definido, sino más bien como un espacio 
en blanco para ser intervenido, significado y apropiado por las comunidades. Lo anterior supone una expansión radical del formato y del valor de uso del afiche como dispositivo de comunicación para trabajadores y pobladores. Ejemplo de esto es el afiche desarrollado por el Tallersol para el Sindicato Lloyd Chile, cuya iconografía central consiste en la imagen de un par de manos sosteniendo una pancarta en blanco y un afiche realizado por la APJ para la huelga del Sindicato Industrial Minero Schwager a partir de un montaje fotográfico que cedía espacio a la convocatoria en cada momento. Resulta interesante destacar cómo este dispositivo tensiona algunas lecturas históricas sobre la misma APJ criticada en palabras de la teórica Nelly Richard "por su referencia ilustrativa a la contingencia de las luchas sociales" (2007, p. 26). A diferencia de lo planteado vemos que la contingencia aparece en estos afiches como una apertura que, lejos de ilustrar la línea de propaganda de un partido político del modo que lo hicieron las brigadas, procura dar espacio para que luego otros ilustrasen a pulso sus propias respuestas al acontecer. Tanto como el compromiso con la contingencia, otro elemento que caracterizó la trayectoria de ambos grupos fue la capacidad de construir su propia trinchera gráfica a partir de la autodeterminación de su quehacer, con independencia de partidos y otras instituciones. Tanto la APJ como el Tallersol llegaron a agrupar un gran número de artistas y trabajadores culturales que en un contexto de creciente fragmentación y competencia apostaron por la colectivización de la creación gráfica. Esta renuncia a la autoría individual, incluso en el caso de piezas elaboradas individualmente a solicitud del colectivo, fue analizada por Patricio Rueda, integrante de la APJ, en una columna publicada en el primer boletín de la Asociación de Pintores y Escultores de Chile (APECH) donde afirma que: "esta tendencia se ha venido expresando como respuesta al exacerbado individualismo que entre otros factores promueve la cultura oficial" (Rueda, 1985). El compromiso colectivo que forjaron fue concebido por sus integrantes como parte de una militancia social que, al igual que la de otras agrupaciones artísticas y culturales del período, estuvo abocada a fortalecer el tejido social antes que a una disputa por la toma del poder. Junto con esto, la autonomía respecto a otras estructuras políticas e institucionales les permitió cuidar su independencia y que sus redes de colaboración crecieran amplias, heterogéneas y sin sectarismos dentro de la oposición a la dictadura. Dado que coincidían distintas militancias políticas en cada colectivo, no era posible identificarlos como grupos de una sola tendencia o sector; más bien y como propone Antonio Kadima, se trataba de organizaciones que "no tenían partido, porque tenían todos los partidos" (Kadima, 2013).

\section{Complicidades gráficas: la producción de un vínculo social gráfico}

El sentido de respuesta, colectividad y autonomía que compartieron, tuvo como correlato un proceso productivo que se caracterizó por el desarrollo de un entramado cómplice y solidario constituido por quienes hicieron posible la producción de cada afiche. Al analizar las distintas etapas de producción de una pieza gráfica, es posible observar como la APJ y el Tallersol van conformando una trama de complicidad política y por lo general afectiva, sostenida en la gestación de un vínculo social gráfico.

Desde un primer momento, la relación con las contrapartes se forjó desde una colaboración activa, que lejos de un trato clientelar, se entablaba a partir de la confianza y el mutuo reconocimiento. Las organizaciones 


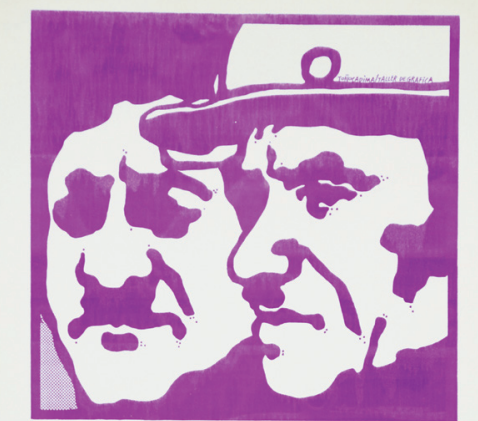

1980 Noviembre 1981

Sindicato de Trabajadores $\mathrm{N}^{\circ} 2$ H.S.A.S.A.

Figura 4. Sindicato de trabajadores $\mathrm{N}^{\circ} 2$ H.S.A.S.A., (Afiche abierto) Toño Kadima / Taller de Gráfica [Tallersol], 1980, offset matriz de papel, $36,5 \times 25,5 \mathrm{~cm}$. Fuente: Archivo Memoria de la Resistencia, Tallersol. que requerían afiches solían aportar con fotos y una consigna y, cuando correspondía, también con los logos o los nombres de otras organizaciones que suscribían a la denuncia o convocatoria. Dado que el afiche era un medio económico y eficaz, se convirtió en una herramienta de uso transversal en distintos espacios. Con el tiempo, y a medida que eran reconocidos por esta labor, ambos colectivos comenzaron a ser más solicitados y así ampliaron el alcance de sus redes dentro del movimiento. El vínculo con las organizaciones que llegaron a solicitar material tomó distintas formas según la regularidad de los pedidos, el grado de involucramiento en el proceso de factura y las formas en que se resolvía su financiamiento. Del conjunto, es posible distinguir tres grupos: aquellas organizaciones que llegaban con encargos ocasionales según la contingencia, como los estudiantes para sus elecciones universitarias, las ollas comunes en poblaciones y los actos culturales en parroquias; otras con las que estaban en permanente contacto, como el vínculo con las peñas para el Taller de Nueva Gráfica y confederación de sindicatos como la coNSTRAMET (Confederación de Trabajadores Metalúrgicos) para la APJ; y luego un tercer grupo constituido por espacios de coordinación de los que ellos mismos fueron parte, como el Coordinador Cultural.

En un segundo momento productivo, este vínculo social gráfico toma lugar en la relación con quienes estaban a cargo de las tecnologías gráficas requeridos para el diseño e impresión de los afiches. El uso de técnicas de impresión industrial dependía de instalaciones de mayor envergadura, por lo que fue necesario acercarse a los operarios de centros de fotocopiado barrial, así como a los dueños y trabajadores de las imprentas, a los mismos prensistas y fotomecánicos a cargo. El vínculo se hizo tan habitual que con algunas imprentas se llegó a construir una red de confianza en el barrio de Los Sacramentinos, en calle San Diego, en el centro de la ciudad de Santiago. Por lo general, ellos accedían en función del tiempo y la seguridad a imprimir el material durante los turnos de noche. El sentido de urgencia acompañaba todo el proceso, y la sensación de que en cualquier momento podían descubrirlos fue un temor compartido que no impidió el apoyo de los prensistas. Este lazo de complicidad descansaba sobre un vínculo político y de mutuo aprendizaje en torno a la gráfica: "el técnico, el que pertenecía a la industria gráfica, aportaba, y uno aportaba del otro lado, pero trabajamos de igual a igual" (Rueda, 2013).

Un tercer momento en que entra en despliegue el desarrollo de un vínculo social gráfico está asociado a las instancias de pedagogía y socialización de técnicas gráficas y herramientas de comunicación popular que ambos colectivos llevaron a cabo en sedes comunitarias y sindicatos. Desde el momento en que la APJ y el Tallersol son fundadas, se sumaron a la proliferación de talleres artísticos que se expandieron a mediados de los setenta como parte del ciclo de repliegue cultural en zonas populares. Estos tuvieron como objetivo no solo ofrecer una actividad para la recreación y el encuentro entre los participantes -cuestión de por sí necesaria-, sino socializar su conocimiento y técnicas para que las organizaciones populares pudieran producir sus propios medios de comunicación gráfica sin tener que depender de terceros. La APJ los llamó talleres de gráfica y comunicación social, y para el Tallersol fueron talleres de gráfica popular y escuelas de verano, donde capacitaron a los integrantes de estas organizaciones para resolver la producción de afiches, boletines y diarios murales, utilizando ma- 


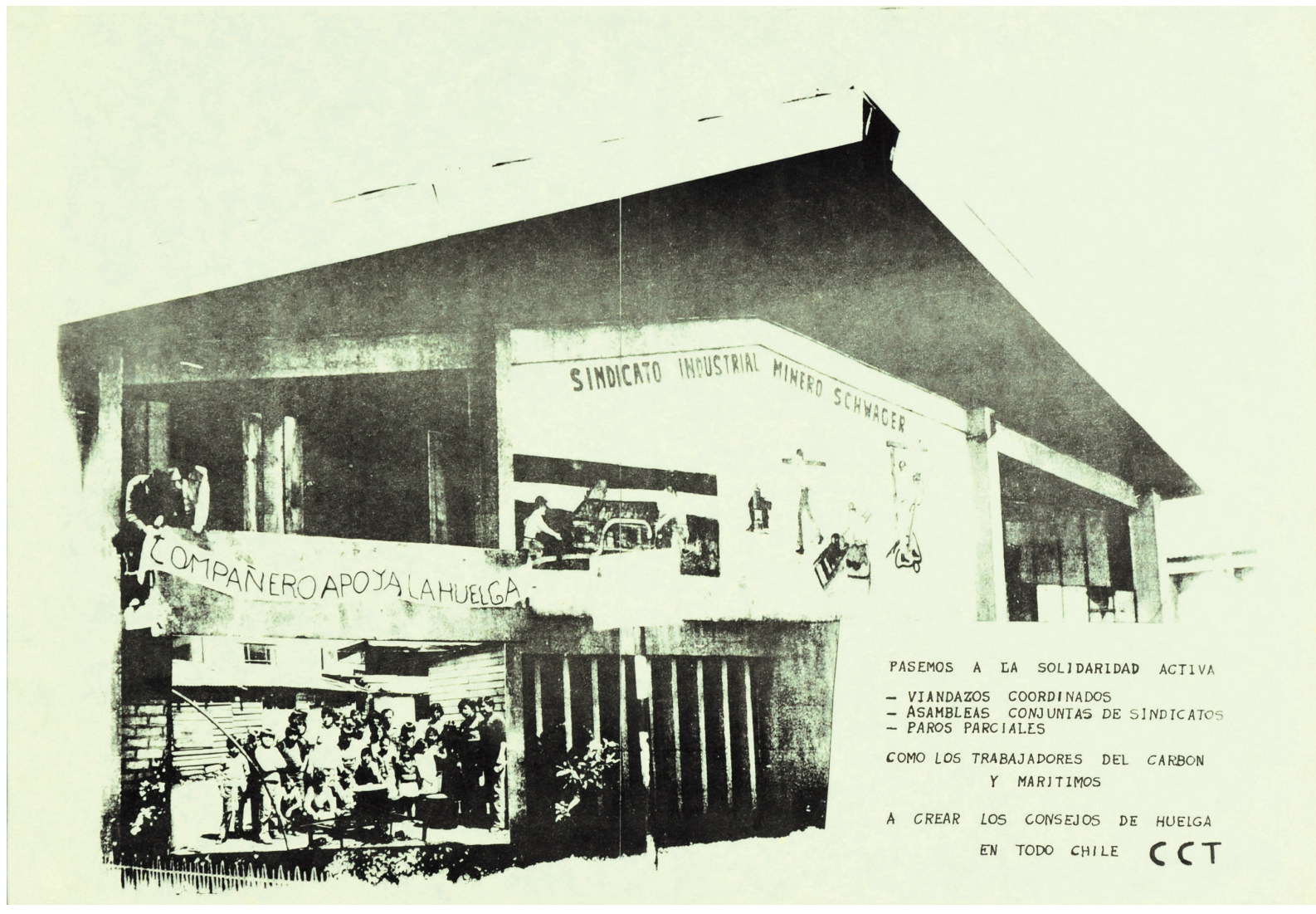

teriales y medios de reproducción económicos. Adicionalmente, los instruyeron sobre el recorrido de fabricación de los afiches, que incluía los datos de lugares donde comprar el papel y las tintas, así como las fotomecánicas e imprentas con que era posible trabajar en aquellos años. Estas instancias pedagógicas buscaban potenciar la autonomía productiva de las organizaciones y aumentar el número de personas que pudieran asumir las tareas gráficas que ellos desempeñaban. Como plantea Juan Carlos Gallardo, del taller de serigrafía del Tallersol: "nosotros queríamos que la gente tuviera la capacidad de autogenerarse sus recursos, y ese era el objetivo del taller y lo fue siempre" (Gallardo, 2013). A pesar de que en la mayoría de los casos las organizaciones seguían pidiéndoles apoyo al momento de elaborar su propio material, el objetivo final consistía en impulsar a que cualquiera pudiera asumir el oficio gráfico dentro de su espacio.

\section{Manipulación y adaptación de las tecnologías gráficas}

Finalmente, un último elemento que caracterizó la politización de la producción gráfica en dictadura, tiene relación con la ampliación de las posibilidades técnicas disponibles a partir de la adaptación e intervención de materiales y tecnologías. La experimentación fue otra dimensión política en el quehacer de ambos colectivos que estuvo dirigida, entre otras cosas, a ampliar su presencia en el espacio público y con ello llegar con sus afiches a cada vez más personas. Como ellos mismos declararon en una de las actas de las jornadas de reflexión gráfica desarrollada en conjunto por ambas organizaciones, la gráfica comenzó por abrir (APJ y Tallersol, 1985) los espacios públicos y

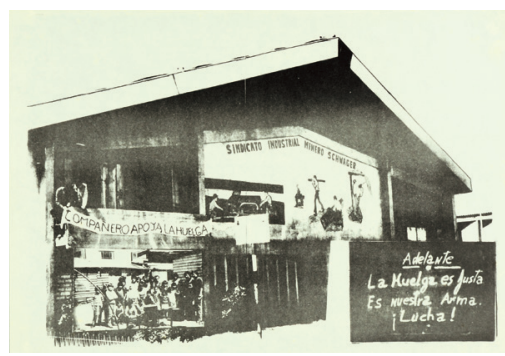

Figura 5. Afiche abierto, APJ, año desconocido, serigrafía, 25,5 ×36,5 cm. Fuente: Archivo personal Hugo Sepúlveda.

Figura 6. Afiche abierto, APJ, año desconocido, serigrafía, 25,5 × 36,5 cm.. Fuente: Archivo personal Hugo Sepúlveda. 


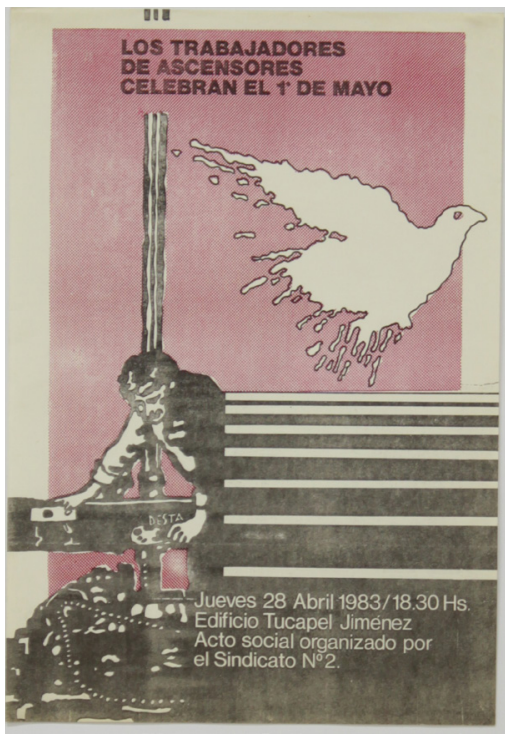

Figura 7. Trabajadores de ascensores celebran el $1^{\circ}$ de mayo, Taller de Gráfica [Tallersol], 1982, offset matriz de papel, $35,5 \times 34,5 \mathrm{~cm}$. Fuente: Archivo Memoria de la Resistencia, Tallersol. comunitarios afectados por la represión, con el uso de técnicas artesanales como el mimeógrafo, la serigrafía y la hectografía, que permitía una mayor autonomía del trabajo. En segunda instancia, se pasó a la conquista (APJ y Tallersol, 1985) de estos espacios mediante el empleo del offset y la fotocopia, que hicieron posible -gracias a la automatización de la seriación- ampliar tirajes y aumentar la presencia e incidencia de los afiches producidos. La APJ incorporó la serigrafía desde sus inicios, ya que uno de sus integrantes, Hugo Sepúlveda, contaba con un taller de serigrafía en su propia casa (anticipando el golpe militar, lo había montado con otros militantes de las JJCC precisamente para fines de comunicación política). Este taller tenía la cualidad de ser un medio portátil que bajo la forma de una maleta serigráfi$\mathrm{ca}$, les permitió llevar el taller a las poblaciones y sindicatos donde enseñaron la técnica. Cuando necesitaron un taller de mayor tamaño, por el tiraje o las dimensiones de las impresiones, acudieron a las instalaciones del Taller 666 y del Taller de Artes Visuales (TAV) y, por cierto, también a las que tendría el Tallersol luego de que Lincoln Cushing, investigador gráfico norteamericano de visita, donará un taller serigráfico al centro cultural en 1985.

En una línea de trabajo más industrial, el uso del offset conllevó un encarecimiento de los costos de producción, sobre todo en relación a la utilización de la matricería metálica. Ante esto, los gráficos de ambos colectivos experimentaron utilizando matrices de papel, la que permitía disminuir los costos del metal, imprimir en formatos menores que el medio mercurio, y borrar las evidencias de la impresión con mayor facilidad. Esto tuvo como resultado afiches de una particular resolución, donde la impresión en offset se deja ver deslucida y desgastada debido a la absorción de la tinta en el papel, pero con una capacidad de reproductibilidad imposible de lograr en otras técnicas. En relación a la fase de diseño, también es posible identificar estrategias que permitieron ampliar la reproducción del material y aumentar el impacto de cada pieza. El ya descrito formato de afiche abierto forma parte de esta búsqueda, así como también el caso de la Serie 1984 realizada por la APJ compuesta por 27 pliegos de $45 \times 35 \mathrm{~cm}$ que al ser dispuestos en conjunto conforman una obra de escala mural. En este gesto de obra gráfica expandida, el uso de los muros no solo se amplía, sino invita a otros a seguir incorporando nuevos pliegos como parte de un mural en permanente expansión. Lo que se observa tanto con la portabilidad de los talleres serigráficos, en la alteración de la matriz del offset, y la experimentación con grandes formatos a partir de la suma de distintas piezas gráficas, son operaciones que dieron lugar a un saber gráfico que se alejó del uso estandarizado de la industria y de aquellos recursos formales de la academia, para habilitar innovaciones incorrectas, como diría Kadima- que emergieron desde el deseo de socializar las técnicas, la economía de recursos y el apremio continuo.

\section{Conclusiones}

Tanto en la APJ como en el Tallersol prevaleció la búsqueda por hacer frente a la dictadura desde una trinchera propia que les permitiera echar mano a sus saberes como artistas, trabajadores de la cultura y diseñadores autodidactas, a la vez que como militantes sociales y activistas gráficos. La politización de la gráfica no solo como herramienta, sino como práctica política, excede la dimensión iconográfica o el contenido de las consignas impresas con que suele estudiarse la historia del afiche y el cartel político.

La dimensión intangible de la producción gráfica trata de aquello que queda 


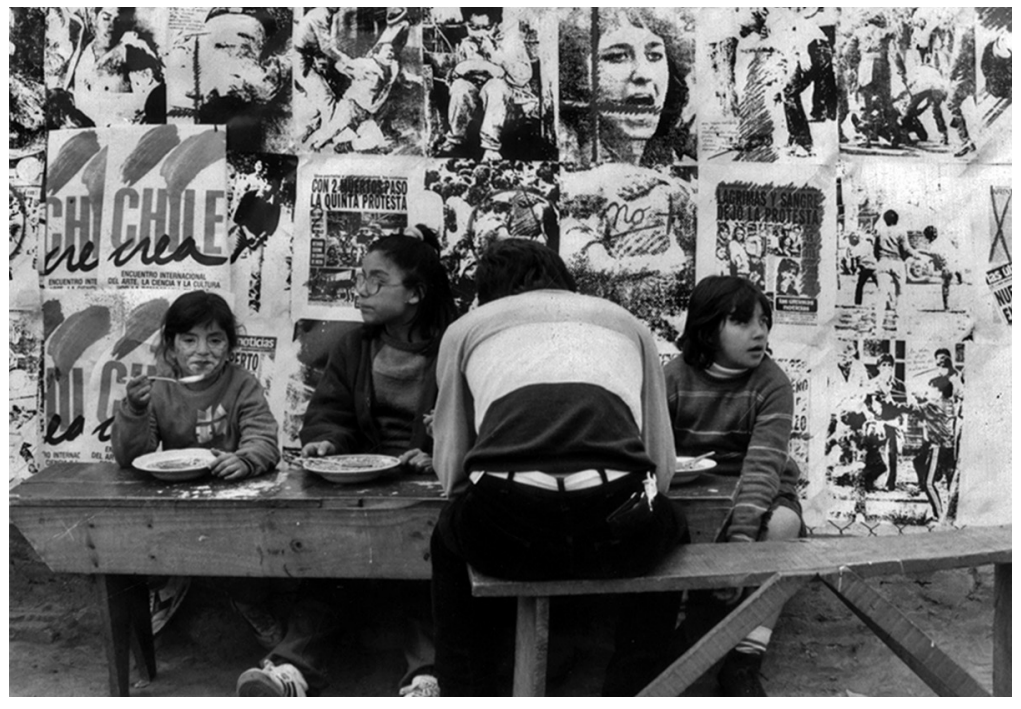

implícito en los gritos de las consignas, se trata de una dimensión práctica, procesual, donde se inscribe una política del hacer que no responde a programas de partido, sino al reconocimiento de que en plena dictadura, cuando el tejido social estaba siendo destruido, la opción por el trabajo colectivo, la complicidad en la colaboración con otros y al servicio de las necesidades de las organizaciones populares, constituía el marco general a una trinchera gráfica en resistencia.

Así, al abordar el afiche político con un énfasis procesual, con una mirada micropolítica, nos encontramos con la potencia de este espacio donde se fraguan gráficas y tejidos sociales conjuntamente. Si respecto a la atomización, la principal estrategia de acción fue el despliegue de un vínculo social gráfico y la opción por el trabajo colectivo, ante la escasez de recursos supieron adaptar los medios disponibles, intervenir las tecnologías y potenciar la fuerza del recurso mínimo como prácticas de resistencia.

La relación entre gráfica y política durante la dictadura en Chile no se agota en el soporte impreso una vez que lo entendemos como una práctica de resistencia y producción micropolítica. Atender esta dimensión, nos permite a su vez pensar el modo en que se hace presente esta memoria de resistencia gráfica en la práctica de generaciones actuales que han vuelto a tomarse y empapelar las calles junto a la movilización social en plena democracia.

Este es el caso de colectivos gráficos que han nacido al alero del movimiento estudiantil de los últimos años donde reverbera esta herencia crítica en la experiencia del Taller de Serigrafía Instantánea, Estudiantes por Chile, el Taller Mano Alzado, la Brigada de Propaganda Feminista, Seri-Insurgentes, y Ser \& Gráfica, entre muchos otros. En este sentido vemos como la creación colectiva, la autonomía política, la participación dentro del movimiento social y por cierto, la marcada preferencia por el uso de técnicas artesanales, con las que van experimentando, tal como la xilografía, y en especial la serigrafía, son elementos que se vinculan directamente con el modo en que comprendieron la trinchera gráfica los integrantes de la APJ y el Tallersol. Una trinchera gráfica que sigue reverberando al hacerse presente y parte de las luchas sociales que vuelven a ocupar el espacio público con vías de profundizar la democracia y erradicar las herencias que aún subsisten del período dictatorial.

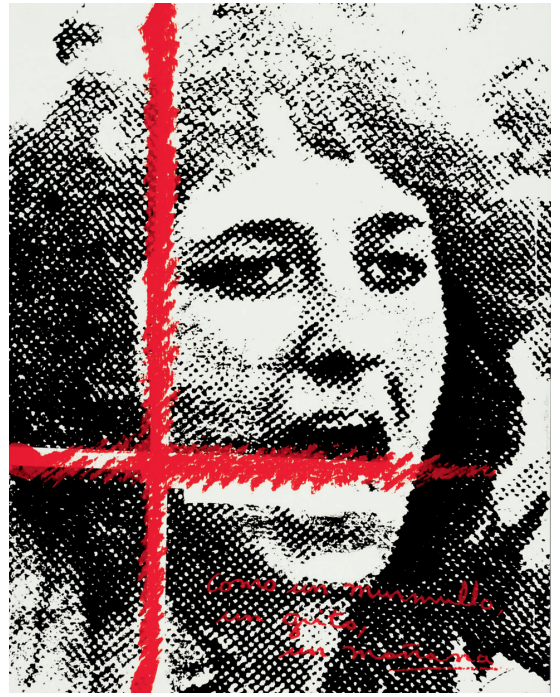

Figura 8. Fotografía 'Serie 1984' de la APJ en población La Victoria, 1984. Fuente: Archivo personal de Cucho Márquez.

Figura 9. Afiche de la 'Serie 1984', 1984, APJ. Fotocopia y serigrafía. Fuente: Archivo personal de Havilio Pérez. 


\section{Referencias bibliográficas}

Álvarez, P. (2004). hDGch Historia del diseño gráfico en Chile. Santiago: Consejo Nacional del Libro y la Lectura.

Benjamin, W. (2005). El autor como productor. (Trad. B. Echeverría) México: Itaca, 24-25.

Castillo, E. (2009). El cartel en Chile: una tradición pendiente. Revista 180 (24), 36-43.

Cristi, N. y Manzi, J. (2016) Resistencia Gráfica. Dictadura en Chile. APJ-Tallersol. Santiago: LOM.

Cortés, A. (1937). Ensayo para una reseña de la historia del affiche en Chile: su importancia y progreso. Revista de Arte 3 (15), 1-4.

Longoni, A. (2009). Activismo artístico en la última década en Argentina: algunas acciones en torno a la segunda desaparición de Jorge Julio López. Errata\#-Revista de Artes Visuales (o), 16-35.

López, M. A. (2014). Acción gráfica. En: Perder la forma humana. Una imagen sísmica de los años ochenta en América Latina (pp. 319-321). Madrid: Museo Nacional Centro de Arte Reina Sofía.

Errázuriz, L. H. y Leiva. G. (2012). El golpe estético: dictadura militar en Chile: 1973-1989. Santiago: Ocho Libros Editores.

Expósito, M., Vidal, A. y Vindel, J. (2014). Activismos Artísticos. En: Perder la forma humana. Una imagen sísmica de los años ochenta en América Latina (pp. 279-283). Madrid: Museo Nacional Centro de Arte Reina Sofía.

Pérez, A. (1986). La creación artística como lenguaje de resistencia a la dictadura militar. Recuperado de: http://rea.uchile.cl/alberto_perez/media/escritos/ la_creacion_artistica.pdf.

Rueda, P. (1985). La práctica colectiva en la producción plástica. Apech (1), p. 14. Recuperado de: http://centrodedocumentaciondelasartes.cl/g2/collect/cedoc/ images/pdfs/5846.pdf

Richard, N. (2007). Márgenes e instituciones. Arte en Chile desde 1973. Santiago: Metales Pesados.

Vico, M. y Osses, M. (2009). Un grito en la pared: psicodelia, compromiso político y exilio en el cartel político chileno. Santiago: Ocho Libros Editores.

Valdebenito, M. (2010). Tinta papel, ingenio. Los Panfletos políticos en Chile 1973-1990. Santiago: Ocho Libros Editores.

\section{Actas y documentos}

APJ y Tallersol (1985). Jornada de intercambio de experiencia (diciembre de 1985). Santiago.

El Mercurio (1973) Bando $n^{\circ} 32$, Santiago: Chile, 26 de septiembre.

\section{Entrevistas}

Díaz, A. (28 de agosto de 2013). Entrevista personal. Santiago.

Gallardo, J.C. (18 de junio de 2013). Entrevista personal. Santiago.

Kadima, A. (17 de junio de 2013). Entrevista personal. Santiago.

Pérez, H. (20 de agosto de 2014). Entrevista personal. Santiago.

Rueda, P. (30 de junio de 2013). Entrevista personal. Santiago. 